\title{
REVIEW
}

\section{A novel view of the adult bone marrow stem cell hierarchy and stem cell trafficking}

\author{
MZ Ratajczak
}

This review presents a novel view and working hypothesis about the hierarchy within the adult bone marrow stem cell compartment and the still-intriguing question of whether adult bone marrow contains primitive stem cells from early embryonic development, such as cells derived from the epiblast, migrating primordial germ cells or yolk sac-derived hemangioblasts. It also presents a novel view of the mechanisms that govern stem cell mobilization and homing, with special emphasis on the role of the complement cascade as a trigger for egress of hematopoietic stem cells from bone marrow into blood as well as the emerging role of novel homing factors and priming mechanisms that support stromal-derived factor 1-mediated homing of hematopoietic stem/ progenitor cells after transplantation.

Leukemia (2015) 29, 776-782; doi:10.1038/leu.2014.346

\section{INTRODUCTION}

It is a rule in science that visionary ideas need time for acceptance and as Max Planck stated 'one thing is important in science-only courageous people win'. To support this as an example, the idea of using blood transfusions for treatment was conceived centuries ago, but it needed Karl Landsteiner, to open the door to transfusion medicine. ${ }^{1}$

With time, it also became obvious that hematopoietic tissues in addition to blood cells also contain stem cells. Historically, the term 'stem cell' was first coined in the middle of nineteenth century by Ernst Haeckel. ${ }^{2}$ In the second half of the twentieth century, James Till and Ernest McCulloch ${ }^{3}$ presented functional evidence for the presence of hematopoietic stem/progenitor cells in mice, and for half a century human hematopoietic stem cells have been successfully used in treating several hematopoietic metabolic and recently even some autoimmune-based disorders. ${ }^{4}$ The breakthrough discovery that enabled the introduction of hematopoietic transplants into the clinic was the discovery of histocompatibility antigens. ${ }^{5}$

Stem cells are currently not only aspirated from bone marrow but also isolated from mobilized blood ${ }^{6}$ and from umbilical cord blood. ${ }^{7}$ The remaining clinical problems are the existence of poor mobilizers, which require more efficient mobilization strategies, and, in the case of cord blood transplants, the low number of hematopoietic stem cells, which requires the development of strategies for efficient ex vivo expansion or to improve homing of these cells to the bone marrow after transplantation.

Moreover, because of the success in the application of stem cells to treat hematopoietic disorders, investigators in several other clinical specialties are looking for a source of stem cells that can be safely and efficiently used to treat damaged organs (e.g., heart, spinal cord or liver). Therefore, the quest continues for more efficient treatment strategies using cells with broader differentiation potential that can be isolated, for example, from hematopoietic tissues. ${ }^{8}$

\section{STEM CELL THERAPIES}

The idea of using stem cells in tissue/organ regeneration, which has become a basic concept of regenerative medicine, is still awaiting identification of a pluripotent stem cell that can be safely and efficiently used in the clinic. This search has focused on embryonic stem cells, genetically modified postnatal cells and unmodified adult stem cells. ${ }^{8}$

Both embryonic stem cells and induced pluripotent stem cells, which are genetically manipulated cells derived from postnatal tissues, are endowed with undisputed multigerm layer differentiation potential but face the problem of teratoma formation, which keeps them on hold for applications in patients. ${ }^{9}$ The first clinical trials currently running in Japan in patients suffering from acute macular degeneration will try to address this issue. However, if any improvement is observed, the next step will be to distinguish between a real effect of stem cell therapy (the formation of new retinal cells from induced pluripotent stem cells in patients) from paracrine effects of these cells on the endogenous stem cells in the retinal pigment epithelium. On the other hand, developmentally early stem cells isolated from adult tissues are very rare and, as of today, are difficult to expand and differentiate ex vivo. ${ }^{8}$

Nevertheless, stem cells isolated from adult tissues are so far the only cells used in clinical settings with an attempt to regenerate non-hematopoietic tissues. More than a decade ago, the concept of stem cell plasticity was proposed, which was based on the assumption that hematopoietic stem cells are plastic, meaning that they may dedifferentiate and become committed to stem cells for various organs/tissues (e.g., heart, brain, liver, bone or skeletal muscle). ${ }^{10}$ This hypothesis, however, has been refuted, and alternative explanations for postulated stem cell plasticity have been proposed.

First, hematopoietic stem cells or other types of stem cells used in therapy, such as mesenchymal stem cells or the so-called cardiac stem cells, are a rich source of soluble growth factors,

Stem Cell Biology Program, Stella and Henry Hoenig Endowed Chair, Stem Cell Institute at James Graham Brown Cancer Center, University of Louisville, Louisville, KY, USA Correspondence: Professor MZ Ratajczak, Stem Cell Biology Program, Stella and Henry Hoenig Endowed Chair, Stem Cell Institute at James Graham Brown Cancer Center, University of Louisville, 500 South Floyd Street, Room 107, Louisville, KY 40202, USA and Department of Regenerative Medicine, Warsaw Medical University, Poland. E-mail: mzrata01@louisville.edu

The Karl Landsteiner distinguished lecture presented during life achievement award ceremony from the German Society of Transfusion Medicine and Immunohematotherapy, 47th Annual Meeting of the Society, Dresden, Germany on 9 September 2014.

Received 4 November 2014; revised 21 November 2014; accepted 1 December 2014; accepted article preview online 9 December 2014 ; advance online publication, 27 January 2015 
cytokines, chemokines, and bioactive lipids that may inhibit apoptosis and promote angiogenesis in damaged organs. ${ }^{11,12}$ Second, in addition to soluble factors, stem cells used as therapeutics also secrete extracellular microvesicles, which may directly stimulate damaged cells and transfer mRNA, miRNA and mitochondria to promote regeneration. ${ }^{13}$ Finally, cells used for therapy and isolated, for example, from bone marrow, mobilized blood and cord blood also contain other types of stem cells besides hematopoietic stem cells, including mesenchymal stem cells, endothelial progenitors and developmentally early stem cells such as, for example, very small embryonic-like stem cells. ${ }^{8,14-16}$

The future of regenerative medicine relies on the identification of an efficient source of pluripotent stem cells that, in combination with organic or synthetic scaffolds, can be safely and efficiently used in tissue or organ regeneration. Currently, much effort is being dedicated to solving the problem of the tumorigenecity of embryonic and induced pluripotent stem cells, ${ }^{9}$ as well as to harness the paracrine effects of adult stem cells. ${ }^{12}$ Another important challenge is to expand ex vivo rare, developmentally early stem cells isolated from adult tissues.

\section{DEVELOPMENTAL ORIGIN OF HEMATOPOIETIC STEM CELLS}

Although hematopoietic stem cells are the best-studied stem cell population so far, several questions remain unanswered and await clarification. The first question that seems not yet to be fully resolved is the developmental origin of these cells. Intriguingly, the first primitive hematopoietic stem/progenitor cells that are detectable in the embryo are specified in extraembryonic tissues (the extraembryonic mesoderm) in the so-called hematopoietic blood islands in the yolk sac. ${ }^{17}$ On the other hand, the first stem cells that become specified from the epiblast and give rise to all three germ layers in the developing embryo are primordial germ cells, which carry developmental totipotency to succeeding generations and are the precursors of gametes. ${ }^{18}$ Shortly after their specification in the proximal epiblast, primordial germ cells enter the extraembryonic mesoderm, make a turn and then migrate back through the embryo proper towards the genital ridges, where they establish gametogenesis. During this migration, primordial germ cells are amplified in number. Interestingly, this moment in migration, when they begin their journey through the extraembryonic mesoderm, correlates in time and space with the formation of the first hemangioblasts and the generation of hematopoietic islands at the bottom of the yolk sac. ${ }^{19}$ Hemangioblasts, in turn, give rise to both primitive hematopoietic cells and endothelial progenitors.

Another somewhat open and challenging question is the origin of definitive hematopoietic stem cells in the developing embryo. Most investigators accept the idea that definitive hematopoietic stem cells emerge from hemangiogenic endothelium in the dorsal aorta in response to shear stress from circulating blood, which depends on the development of a beating heart. ${ }^{20,21}$ Nevertheless, at this point it is still not clear how great a contribution to adult hematopoiesis is made by primitive hematopoietic stem cells, which are specified in extraembryonic yolk sac blood island mesoderm from hemangioblasts and may move into the circulation. $^{19}$ Alternatively, because hematopoietic stem cell precursors are developmentally associated with blood island endothelium, when the endothelium establishes the circulatory vessel network in the developing embryo, they could also migrate associated with the developing vessels. Finally, it is also possible that, during their migration to the genital ridges through the embryo proper, primordial germ cells may also give rise to a population of precursors of definitive hematopoietic stem cells. ${ }^{22}$ In support of this latter possibility, the formation of definitive hematopoietic stem cells in the dorsal aorta is spatially and temporally connected with the wave of primordial germ cells migrating through the so-called aorta-gonads-mesonephros region to the genital ridges in the embryo proper.

This temporal and spatial connection between the migration of primordial germ cells and the formation of primitive and definitive hematopoietic stem cells raises another challenging question about the potential developmental link between these both cell populations. Interestingly, several papers have described the sharing of chromosomal aberrations between germline tumors and leukemias or lymphomas, which suggests their common clonal origin..$^{23-25}$ Similarly, both muirne and human hematopoietic stem cells express several pituitary and gonadal sex hormone receptors (submitted) and respond to stimulation by sex hormones, ${ }^{26,27}$ and, as recently reported, germline-derived cells share with hematopoietic cells a functional erythropoietin receptor. ${ }^{28}$ Furthermore, it has been demonstrated that murine primordial germ cells isolated from embryos, stem cells isolated from murine testes, and teratocarcinoma cell lines can be specified into hematopoietic stem/progenitor cells. ${ }^{29,30}$ Moreover, Sall4-an important developmental factor, is expressed in both hematopoietic and germ cells. ${ }^{31}$ On the other hand, bone marrow may contain cells that give rise to gametes. ${ }^{32,33}$ Thus, further research is needed to answer the intriguing question of how much germline developmental potential is retained by hematopoietic stem cells.

\section{A NOVEL VIEW OF THE HIERARCHY OF BONE MARROW- RESIDING STEM CELLS}

The next few years should also yield an answer to the intriguing question of whether stem cells that originated in the extraembryonic mesoderm in yolk sac or epiblast or are derived from migrating primordial germ cells can colonize the fetal liver and subsequently migrate to the developing adult bone marrow. Such cells could be potential precursors of long-term repopulating hematopoietic stem cells as well as mesenchymal stem cells and endothelial progenitor cells.

In fact, several investigators have described populations of stem cells with broader potential to cross germline boundaries. Such cells have been described by many investigators and, depending on the methods for how they were isolated, assigned different names: for example, spore-like stem cells, ${ }^{34}$ multipotent adult stem cells, ${ }^{35}$ multilineage-differentiating stress-enduring cells, ${ }^{36}$ multipotent adult progenitor cells, ${ }^{37}$ unrestricted somatic stem cells, ${ }^{38}$ marrow-isolated adult multilineage-inducible cells ${ }^{39}$ and, as described by us a decade ago and mentioned above, very small embryonic-like stem cells. ${ }^{14-16}$ Reports of the presence of all these stem cell types in adult tissues has created a kind of nomenclatural chaos, and probably several of them described as separate entities are in fact overlapping populations of similar cells (Figure 1).

Further research is needed to establish the relationship between these different types of stem cells and compare their developmental potential side by side.

\section{VERY SMALL EMBRYONIC-LIKE STEM CELLS AS A CHALLENGE TO THE EXISTING STEM CELL HIERARCHY}

Very small embryonic-like stem cells have a distinct morphology that corresponds to the quiescent state of these cells. They are small, have a tiny rim of cytoplasm containing few mitochondria and their nuclei are filled with euchromatin. Molecular analysis of these cells has revealed that they truly express several genes characteristic of pluripotent stem cells, migrating primordial germ cells and hemangioblasts. ${ }^{40}$ As expected for pluripotent stem cells, they also express bivalent domains, and cells from female mice activate the $X$ chromosome. Several groups, including us, have shown that, in appropriate models, these small cells can differentiate into cells from all three germ layers. ${ }^{41-45}$ 


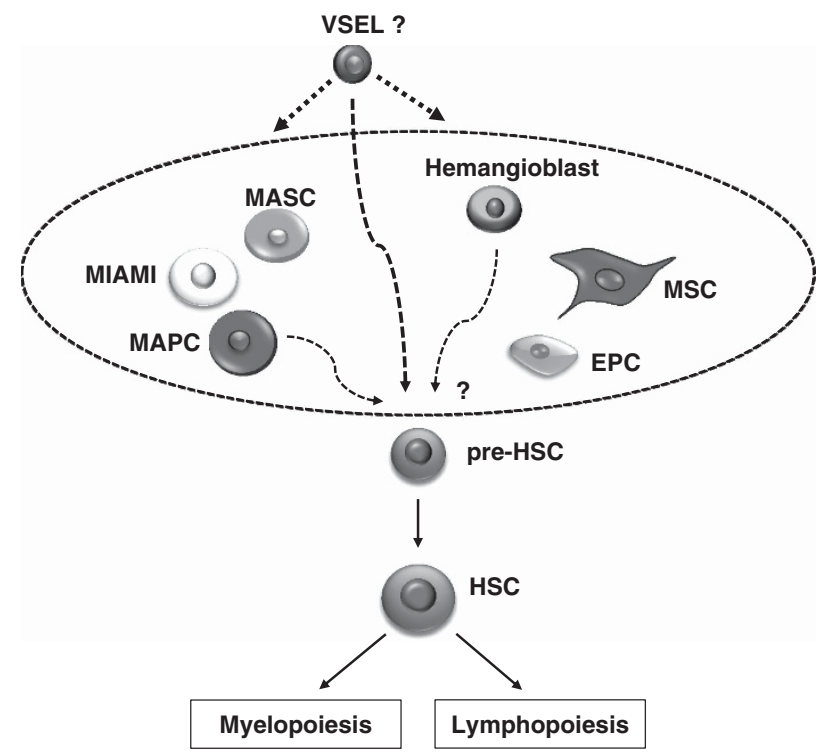

Figure 1. Hypothetical relation of very small embryonic-like stem cells (VSELs) to other multi/pluripotent stem cells identified by several investigators in adult bone marrow, blood and umbilical cord blood. It is very likely that VSELs are primitive, small, dormant, stem cells that, upon proper activation, give rise to other larger multi/pluripotent stem cells identified by other investigators in hematopoietic tissues and may also give rise to hematopoietic/stem progenitor cells, mesenchymal stem cells and endothelial progenitor cells. Abbreviations: EPC, endothelial progenitor cell; HSC, hematopoietic stem cell; MASC, multipotent adult stem cells; MIAMI, marrow-isolated adult multilineage-inducible cell; MAPC, multipotent adult progenitor cell.

However, in contrast to immortalized embryonic and induced pluripotent stem cells, very small embryonic-like stem cells do not contribute to blastocyst development and do not grow teratomas after inoculation into immunodeficient mice. The reason for this is the erasure of imprinting of regulatory sequences encoding certain parentally imprinted genes-a phenomenon that also occurs in primordial germ cells and prevents teratoma formation. ${ }^{46}$ One of the most important imprinted regulatory regions is present within the Igf2-H19 tandem gene, encoding insulin-like growth factor-2 (IGF-2) (a potent stimulator of cell proliferation) and noncoding H19 mRNA, which gives rise to several microRNAs that may inhibit cell proliferation. One of these (miR-675) is responsible for the downregulation of the IGF-1 receptor. ${ }^{47}$ As result of erasure of imprinting at this locus the expression of IGF-2 is downregulated and $\mathrm{H} 19$ upregulated.

The resistance of these small cells to IGF-2 and -1 signaling not only explains their quiescence but also sheds new light on the potential role of these cells in regulating lifespan and cancerogenesis. In further support of this possibility, the number of these cells is high in long-living murine strains, which have very low levels of circulating IGF-1 in blood plasma, and is reduced in shortliving mice with high blood plasma levels of this growth factor. Low levels of circulating IGF-1 in these animals also correlate with their resistance to tumorigenesis, and, vice versa, mice with high levels of circulating IGF-1 frequently develop malignancies. ${ }^{48}$ We propose that resistance of very small embryonic-like stem cells to somatotropic signaling, on the one hand, preserves the pool of these cells for tissue and organ rejuvenation and, on the other hand, protects them from uncontrolled proliferation. Interestingly, mice that have low levels of circulating IGF-1 and as result of this high numbers of very small embryonic-like stem cells in tissues remain fertile at an age $>2$ years, which supports a role for ovarian very small embryonic-like stem cells in giving rise to gamete precursors. $^{49}$ Finally, our data indicate that calorie restriction, prolonged exercise and metformin administration exert positive effects on the number of these cells residing in adult tissues. ${ }^{50}$ These findings indicate new directions for regenerative medicine and modern pharmacology: specific new drugs that attenuate somatotropic signaling may contribute to an increase in lifespan and a reduced risk of cancer.

Although very small embryonic-like stem cells have been shown by several groups to differentiate in vivo and in vitro into cells from various germ lineages, the efficient expansion of these cells ex vivo for therapeutic use is still a problem because of the abovementioned epigenetic changes in imprinted genes. More studies are also needed to compare them with other types of developmentally early stem cells residing in bone marrow (Figure 1).

\section{STEM CELLS AS NONSTOP TRAVELERS}

One important property of hematopoietic stem cells is that they are highly migratory, moving during development between different organs where hematopoiesis takes place and finally reaching the bone marrow, which remains the main hematopoietic organ in an adult organism. ${ }^{51}$ Stem cells may leave their niches, usually after their symmetric division, and circulate in blood to find a new niche and thus keep the pool of stem cells in balance in the bone marrow at distant locations in the body. It has been proposed that they also have a role as 'paramedics' patrolling tissues for potential infections or damage. ${ }^{52}$ In addition to hematopoietic stem cells, other types of stem cells circulate in blood, including mesenchymal stem cells, endothelial progenitors and very small embryonic-like stem cells. The number of all types of these stem cells increases in blood during organ and tissue injuries, infections and other situations, such as after strenuous exercise. ${ }^{53,54}$ These observations indicate that circulating stem cells may have an important role in ameliorating several pathological processes. The number of stem cells circulating in blood is also regulated by a circadian rhythm. ${ }^{55-57}$ Forced egress of stem cells from their niches into blood also occurs during pharmacological mobilization, where their number increases up to 100 times compared with steady-state conditions.

For many years my group has been studying the role of the complement cascade in orchestrating the mobilization of stem cells. ${ }^{58}$ In fact, this evolutionarily ancient proteolytic cascade becomes activated in response to infection, tissue organ injury, strenuous exercise and after administration of stem cells mobilization-promoting drugs, including granulocyte colony-stimulating factor $^{59}$ and CXCR4 inhibitor-plerixafor (AMD3100). ${ }^{60}$

As, the complement cascade is a sensor of environmental changes in adult organisms, it also interacts with two other ancient proteolytic cascades, the coagulation cascade and the fibrynolytic cascade, which, as recently reported, also affect the mobilization process of stem cells. ${ }^{61,62}$ Importantly, all these cascades show a circadian rhythm of activation, with a peak during deep sleep due to hypoxia, and activation of the coagulation and the complement cascades precedes the peak of stem cell release from bone marrow observed in the early morning hours. ${ }^{63}$ Interestingly, we recently observed that C5deficient mice, which do not activate the distal part of the complement cascade, are not only poor mobilizers ${ }^{63}$ but also do not show circadian changes in the number of stem cells circulating in blood.

Circadian oscillation in the number of circulating hematopoietic stem cells in blood, with the peak occurring in the early morning hours and the nadir at night, has been attributed in mice to enhanced tonus of the autonomic nervous system in the early morning hours. ${ }^{56}$ In support of a possible role of this branch of the nervous system, it has been shown that UDP-galactose:ceramide galactosyltransferase-deficient mice, which exhibit aberrant nerve 
conduction and do not release norepinephrine into the bone marrow microenvironment, do not mobilize stem cells. ${ }^{57}$ However, modification of the sympathetic output, as seen in normal human stem cell volunteer donors receiving norepinephrine reuptake inhibitors for depression or $\beta 2$-blockers for hypertension, induces mobilization in a similar manner as normal controls. ${ }^{51}$ Mobilization in these patients was neither enhanced by norepinephrine reuptake inhibitor administration nor suppressed by $\beta 2$-blockers, which is not what one would have expected based on the murine data reported in the literature. This finding may indicate some differences in the role of the vegetative nervous system in the release of hematopoietic stem cells between mice ${ }^{56}$ and humans, ${ }^{51}$ and further studies are warranted to shed more light on this phenomenon.

\section{THE MECHANISM REGULATING EGRESS OF HEMATOPOIETIC STEM CELLS FROM BONE MARROW INTO BLOOD}

Our knowledge about the mechanisms that trigger mobilization of hematopoietic stem cells is increasing. The first and most important step in the mobilization process is their detachment from bone marrow niches, where they are anchored owing to the interaction between the a-chemokine stromal-derived factor 1 (SDF-1) and vascular cell adhesion molecule-1 (VCAM-1), expressed in stem cell niches and, respectively, corresponding to the CXCR4 and a4 31 integrin (VLA-4) receptors expressed on hematopoietic stem/progenitor cells. ${ }^{64}$ Of note, both CXCR4 and VLA-4 receptors are membrane lipid raft-associated receptors, and their incorporation into lipid rafts is essential to their optimal biological function. ${ }^{51,65-67}$

A crucial role in this process is played by the induction of a proteolytic microenvironment in bone marrow due to the release of proteolytic enzymes from granulocytes and monocytes, and this effect has been observed, for example, after the administration of granulocyte colony-stimulting factor. ${ }^{64}$ It has been demonstrated that several proteolytic enzymes released by cells in bone marrow digest proteins involved in the retention of hematopoietic stem cells in the bone marrow microenvironment (e.g., SDF-1 and CXCR4). ${ }^{64,68}$ Interestingly, the crucial proteases involved in this process have not yet been identified, as mice with knockout of multiple proteolytic enzymes, such as matrix metalloproteinase-9, matrix metalloproteinase-2, cathepsin G and elastase, mobilize hematopoietic stem cells in a similar manner as control wild-type mice. ${ }^{59}$ This finding may indicate that their deficiency is compensated by other proteolytic enzymes, and one of the candidates is cathepsin $\mathrm{K}$, which is expressed, for example, by osteoclasts, and direct mobilization studies in cathepsin K-knockout mice could answer this question.

Another previously unrecognized possibility is the involvement of other types of non-proteolytic enzymes. Our recent results indicate the involvement of the lipolytic enzyme hematopoietic cell-specific phospholipase C $\beta 2$ (PLC- $\beta 2){ }^{69}$ Our data indicate that the level of this lipase increases in BM during mobilization, and it is released from neutrophils in response to several promobilization factors (e.g., granulocyte colony-stimulting factor, AMD3100, sphingosine-1-phosphate (S1P) and C5a). PLC- $\beta 2$ is an enzyme that targets (i) truncated isoform of VCAM-1 expressed in stem cell niches and (ii) the glycoplipidglycosylphosphatidylinositol anchor, which is important for lipid raft formation and thus optimal function of CXCR4 and VLA-4, and is required for membrane expression of endogenous complement cascade inhibitors (CD55 and CD59). Thus, after PLC- $\beta 2$ release during mobilization, stem cells are easily detached from their niches, on the one hand, as a result of the removal of truncated VCAM-1 and, on the other hand, due to perturbation of the formation of membrane lipid rafts required for optimal bone marrow-retention signaling from the CXCR4 and VLA-4 receptors. ${ }^{65-67}$ In addition, removal of CD55 and
CD59 from the cell surface leads to enhanced activation of the mobilization-promoting complement cascade.

In support of this mechanism, we observed a mobilization defect in PLC $\beta 2^{-/-}$mice, as evaluated by the number of mobilized leukocytes, Sca- $1^{+} \mathrm{Kit}^{+} \mathrm{Lin}^{-}$cells and colony-forming units of granulocyte-macrophage. ${ }^{69}$ These results indicate that, in addition to proteolytic enzymes, lipolytic enzymes, including PLC- $\beta 2$, are also upregulated in the bone marrow microenvironment during the mobilization process and that PLC- $\beta 2$ promotes mobilization of hematopoietic stem cells by perturbing the bone marrow-retention function of glycoplipidglycosylphosphatidylinositol anchor-associated proteins.

As mentioned above, our results also indicate that activation of the complement cascade is a trigger for mobilization of stem cells, and a major role is played here by cleavage fragments of the fifth complement cascade protein (C5), C5a and desArg C5a. Known also as anaphylatoxins, both these molecules are potent stimulators and chemoattractants of granulocytes and monocytes. Activation of granulocytes and monocytes by C5 cleavage fragments explains the release of proteolytic enzymes and, as mentioned above, also PLC- $\beta 2$. As the result of the coordinated action of proteolytic and lipolytic enzyme mechanisms, hematopoietic stem cell retention in bone marrow niches is attenuated, and these cells are released from their 'anchors'. After release from their niches, stem cells respond to a major chemoattractant in blood, the bioactive phosphosphingolipid S1P. ${ }^{70-72}$ The role of this lipid somewhat challenges the conventional view of the role of SDF-1 gradients between bone marrow and blood plasma in the egress of stem cells. Accumulating evidence indicates that, despite the fact that the SDF-1-CXCR4 axis has an unquestionably important role in the retention of stem cells in bone marrow, the SDF-1 level in blood does not clearly correlate with the mobilization of hematopoietic stem cells. ${ }^{70,73,74}$ By contrast, it has been demonstrated that the level of S1P in blood, even under steady-state conditions, is already high enough to chemoattract stem cells released from their niches. ${ }^{70,72}$ In addition, the high S1P level in blood may be additionally increased by erythrocytes and platelets due to the activation of the complement and coagulation cascades. $^{70}$

Hematopoietic stem cells released from their niches must cross the bone marrow-blood endothelial barrier in bone marrow sinusoids. In this step of the mobilization process, a crucial role is played by neutrophils and monocytes, which, as the first cells to egress from bone marrow into blood, are chemoattracted by $\mathrm{C} 5 \mathrm{a}$ and desArg $\mathrm{C} 5 \mathrm{a}$ cleavage fragments of the activated complement cascade in bone marrow sinusoids. ${ }^{75}$ In response to the gradient of C5 cleavage fragments between bone marrow and blood, granulocytes and monocytes, which are highly enriched in proteolytic enzymes necessary to digest the endothelial barrier, are the first cells to egress from the bone marrow into blood and, by doing so, pave the way for hematopoietic stem cells to follow in their footsteps (Figure 2).

Although there are vast amounts of experimental data on the mechanisms and factors that induce or promote mobilization of stem cells, there is relatively less data on negative regulators of this process. We demonstrated for the first time that heme oxygenase $1(\mathrm{HO}-1)$, which has a well-documented antiinflammatory potential, has an important and heretofore unrecognized role in the retention of hematopoietic stem cells in bone marrow niches by negatively modulating the activation of complement cascade. ${ }^{76}$ Based on this result, the tug of war between complement cascade activation and HO-1 activity becomes an interesting target for developing new mobilization strategies. 


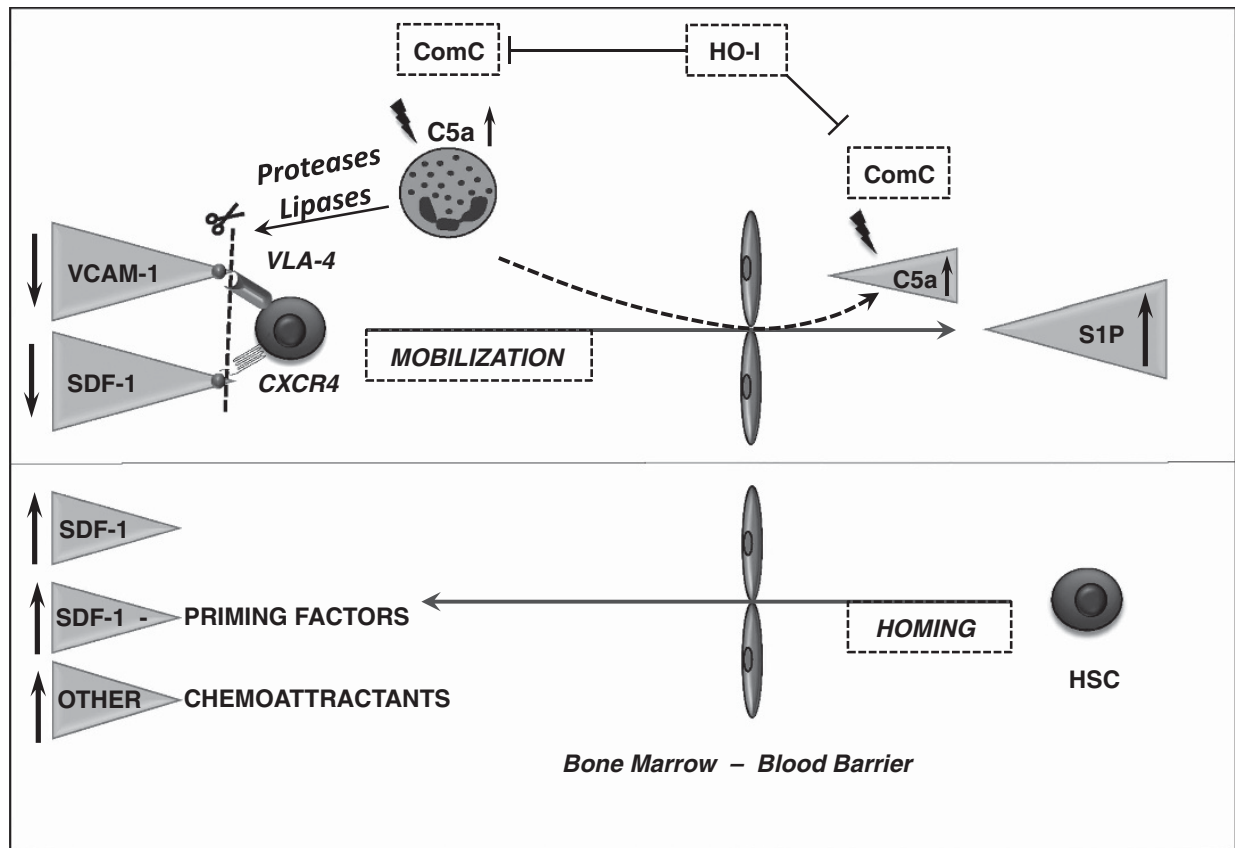

Figure 2. The proposed major mechanism underlying the processes of mobilization and homing of hematopoietic stem cells (HSCs). Mobilization of HSCs (upper panel). Activation of the complement cascade (ComC) is a trigger for the mobilization process. The ComC cleavage fragments $\mathrm{C} 5 \mathrm{a}$ and ${ }_{\text {desArg }} \mathrm{C} 5 \mathrm{a}$ induce proteolytic and lypolytic enzymes from bone marrow-residing granulocytes and macrophages. These enzymes attenuate SDF-1-CXCR4- and VCAM-1-VLA-4-mediated retention of HSCs in bone marrow niches. An increase in the ComC cleavage fragments $\mathrm{C} 5 \mathrm{a}$ and desArg $\mathrm{C} 5 \mathrm{a}$ in $\mathrm{BM}$ sinusoids chemoattracts leukocytes and monocytes from $\mathrm{BM}$ into PB, and these cells are the first to egress from the BM microenvironment and pave the way for HSPCs through the endothelial barrier. HSCs released from their niches are chemoattracted by the S1P gradient between bone marrow and blood. HO-1 is an inhibitor of ComC activation and mobilization of HSPCs. Homing of HSCs (lower panel). HSCs infused into blood respond to a gradient of SDF-1 between bone marrow and blood; however, conditioning for transplantation by chemo/radiotherapy may also upregulate other homing factors, such as S1P and ceramide-1-phosphate (C1P), and increase the level of extracellular nucleotides (ATP and UTP). In addition, LL-37 and $\beta 2$-defensin released from BM stromal cells and osteoblasts increase the responsiveness of HSCs to an SDF-1 gradient by a priming mechanism.

\section{HOMING OF HEMATOPOIETIC STEM CELLS TO THE BONE MARROW}

Migration and bone marrow homing of hematopoietic stem cells after transplantation precedes their final engraftment and is a key factor in successful hematopoietic transplantation. The major role in homing to bone marrow has been assigned to the SDF-1 gradient, which increases after conditioning for transplantation in the bone marrow microenvironment. ${ }^{68,77}$ In the meantime, evidence has accumulated that hematopoietic stem cells also home to the bone marrow in an SDF-1-CXCR4 axis-independent manner. In support of this evidence, (i) $\mathrm{CXCR}^{-/-}$fetal liver hematopoietic stem cells home to bone marrow, ${ }^{78}$ (ii) homing of murine hematopoietic stem cells made refractory to SDF- 1 by incubation and coinjection with a CXCR4 receptor antagonist is normal or only mildly reduced ${ }^{79}$ and (iii) hematopoietic stem cells in which CXCR4 has been knocked down by means of an SDF-1 intrakine strategy are also able to engraft. ${ }^{80}$ These observations open up a new area of investigation to look for homing factors that, based on the aforementioned examples, can compensate for SDF-1 deficiency.

In fact, there are very few chemoattractants that have been identified for hematopoietic stem cells. Besides SDF-1, which is the only known chemokine that chemoattracts these cells, ${ }^{68,77}$ these include bioactive phosphosphingolipids, such as S1P and ceramide-1-phosphate, ${ }^{81}$ and the extracellularly released nucleotides, such as UTP and ATP. ${ }^{82}$ Interestingly, all of these homing factors seem to bind to $G_{\text {ai }}$ protein-coupled receptors. The involvement of these novel homing factors in the homing of hematopoietic stem cells is currently being investigated in my laboratory (Figure 2).
Another important mechanism involved in homing of hematopoietic stem cells that could be explored in the clinic is the socalled priming phenomenon. ${ }^{81}$ Specifically, the responsiveness of stem cells to an SDF-1 gradient is enhanced by the presence of anti-microbial cationic peptides that are part of the innate immunity response, such as (i) the complement cascade cleavage fragment $C 3 a^{83}$ and (ii) cathelicidin (LL-37) and $\beta 2$-defensin, which are induced by $\mathrm{C} 5 \mathrm{~b}-\mathrm{C} 9$ in bone marrow stroma during conditioning for transplantation. ${ }^{84}$ The basis for priming by these factors is their promotion of the incorporation of CXCR4 into membrane lipid rafts, ${ }^{65-67}$ which makes the CXCR4 receptor more responsive to an SDF-1 gradient. ${ }^{65-67,81}$ These domains also act as good sites for crosstalk between various cellular proteins, including cytoskeletal elements. As reported by other investigators, the responsiveness of hematopoietic stem cells to an SDF-1 gradient may also be enhanced by the presence of prostaglandin E2 (ref. 85) and hyaluronic acid. ${ }^{86}$ These findings suggest that the responsiveness of cells to an SDF-1 gradient is modulated by several molecules related to innate immunity and inflammation. ${ }^{58}$ Finally, homing of stem cells into bone marrow could be achieved by inhibiting CD26 on these cells, ${ }^{79}$ an interesting strategy that is being currently tested in cord blood transplants.

\section{CONCLUSIONS AND FUTURE DIRECTIONS}

The paradigms in science shift, and, according to Albert Einstein, 'blind belief in authority is the greatest enemy of truth'. Einstein also stated that 'anyone who has never made a mistake has never tried anything new'. These wise words apply not only to theoretical physicists of the twentieth century, who were 
challenging various scientific paradigms, but also has meaning for the biological sciences and should be remembered at a time of dynamic developments in the area of stem cell research. There are still a lot of questions that need to be answered, with hypothesis testing by independent groups, and new generations of scientists will be needed to verify many of the current paradigms.

\section{CONFLICT OF INTEREST}

University of Louisville as owner of patent on small embryonic-like stem cells and some areas of this technology are licensed to Neostem Inc. (New York, NY, USA). The author does not have any stocks in Neostem or other biotechnological stem cell companies.

\section{ACKNOWLEDGEMENTS}

This work was supported by NIH Grants 2R01 DK074720 and R01HL112788 and the Stella and Henry Endowment to MZR.

\section{REFERENCES}

1 Landsteiner K. Individual differences in human blood. Science 1931; 73: 403-409.

2 Ramalho-Santos M, Willenbring $\mathrm{H}$. On the origin of the term 'stem cell'. Cell Stem Cell 2007; 1: 35-38.

3 Till JE, McCulloch EA. A direct measurement of the radiation sensitivity of normal mouse bone marrow cells. Radiat Res 1961; 14: 213-222.

4 Thomas ED. Bone marrow transplantation from the personal viewpoint. Int $J$ Hematol 2005; 81: 89-93.

5 Snell GD. The Nobel Lectures in Immunology. Lecture for the Nobel Prize for Physiology or Medicine, 1980: Studies in histocompatibility. Scand J Immunol 1992; 36: 513-526.

6 Hénon P. New developments in peripheral blood stem cell transplants. Leukemia 1992; 6: 106-109.

7 Ballen KK, Gluckman E, Broxmeyer HE. Umbilical cord blood transplantation: the first 25 years and beyond. Blood 2013; 122: 491-498.

8 Ratajczak MZ, Jadczyk T, Pędziwiatr D, Wojakowski W. New advances in stem cell research: practical implications for regenerative medicine. Pol Arch Med Wewn 2014; 124: 417-426.

9 Cunningham JJ, Ulbright TM, Pera MF, Looijenga LH. Lessons from human teratomas to guide development of safe stem cell therapies. Nat Biotechnol 2012; 30: 849-857.

10 Mertelsmann R. Plasticity of bone marrow-derived stem cells. J Hematother Stem Cell Res 2000; 9: 957-960.

11 Majka M, Janowska-Wieczorek A, Ratajczak J, Ehrenman K, Pietrzkowski Z Kowalska MA et al. Numerous growth factors, cytokines, and chemokines are secreted by human $\mathrm{CD} 34(+)$ cells, myeloblasts, erythroblasts, and megakaryoblasts and regulate normal hematopoiesis in an autocrine/paracrine manner. Blood 2001; 97: 3075-3085.

12 Ratajczak MZ, Kucia M, Jadczyk T, Greco NJ, Wojakowski W, Tendera M et al. Pivotal role of paracrine effects in stem cell therapies in regenerative medicine: can we translate stem cell-secreted paracrine factors and microvesicles into better therapeutic strategies? Leukemia 2012; 26: 1166-1173.

13 Ratajczak J, Miekus K, Kucia M, Zhang J, Reca R, Dvorak P et al. Embryonic stem cell-derived microvesicles reprogram hematopoietic progenitors: evidence for horizontal transfer of mRNA and protein delivery. Leukemia 2006; 20: 847-856.

14 Kucia M, Reca R, Campbell FR, Zuba-Surma E, Majka M, Ratajczak J et al. A population of very small embryonic-like (VSEL) CXCR4(+)SSEA-1(+)Oct-4+ stem cells identified in adult bone marrow. Leukemia 2006; 20: 857-869.

15 Kucia M, Halasa M, Wysoczynski M, Baskiewicz-Masiuk M, Moldenhawer S Zuba-Surma $E$ et al. Morphological and molecular characterization of novel population of CXCR4+ SSEA-4+ Oct-4+ very small embryonic-like cells purified from human cord blood: preliminary report. Leukemia 2007; 21: 297-303.

16 Ratajczak MZ, Zuba-Surma E, Wojakowski W, Suszynska M, Mierzejewska K, Liu R et al. Very small embryonic-like stem cells (VSELs) represent a real challenge in stem cell biology: recent pros and cons in the midst of a lively debate. Leukemia 2014; 28: 473-484.

17 Galloway JL, Zon LI. Ontogeny of hematopoiesis: examining the emergence of hematopoietic cells in the vertebrate embryo. Curr Top Dev Biol 2003; 53: 139-158.

18 Saitou M. Germ cell specification in mice. Genet Dev 2009; 19: 386-395.

19 Palis J. Primitive and definitive erythropoiesis in mammals. Front Physiol 2014; 5: 3-9.
20 Adamo L, Naveiras O, Wenzel PL, McKinney-Freeman S, Mack PJ, Gracia-Sancho J et al. Biomechanical forces promote embryonic haematopoiesis. Nature 2009; 459: 1131-1135.

21 Lux CT, Yoshimoto M, McGrath K, Conway SJ, Palis J, Yoder MC. All primitive and definitive hematopoietic progenitor cells emerging before E10 in the mouse embryo are products of the yolk sac. Blood 2008; 111: 3435-3438.

22 De Miguel MP, Arnalich Montiel F, Lopez Iglesias P, Blazquez Martinez A, Nistal M. Epiblast-derived stem cells in embryonic and adult tissues. Int J Dev Biol 2009; 53: 1529-1540.

23 Woodruff K, Wang N, May W, Adrone E, Denny C, Feig SA. The clonal nature of mediastinal germ cell tumors and acute myelogenous leukemia. A case report and review of the literatur. Cancer Genet Cytogenet 1995; 79: 25-31.

24 Chaganti RS, Ladanyi M, Samaniego F, Offit K, Reuter VE, Jhanwar SC et al. Leukemic differentiation of a mediastinal germ cell tumor. Genes Chromosomes Cancer 1989; 1: 83-87.

25 Nichols CR, Hoffman R, Einhorn LH, Williams SD, Wheeler LA, Garnick MB. Hematologic malignancies associated with primary mediastinal germ-cell tumors. Ann Int Med 1985; 102: 603-609.

26 Nakada D, Oguro H, Levi BP, Ryan N, Kitano A, Saitoh Y et al. Oestrogen increases haematopoietic stem-cell self-renewal in females and during pregnancy. Nature 2014; 505: 555-558.

27 Selleri C, Catalano L, De Rosa G, Fontana R, Notaro R, Rotoli B. Danazol: in vitro effects on human hemopoiesis and in vivo activity in hypoplastic and myelodysplastic disorders. Eur J Haematol 1991; 47: 197-203.

28 Suszynska M, Poniewierska-Baran A, Gunjal P, Ratajczak J, Marycz K, Kakar SS et al. Expression of the erythropoietin receptor by germline-derived cells-further support for a potential developmental link between the germline and hematopoiesis. J Ovarian Res 2014; 7: 66.

29 Rich IN. Primordial germ cells are capable of producing cells of the hematopoietic system in vitro. Blood 1995; 86: 463-472.

30 Ohtaka T, Matsui Y, Obinata M. Hematopoietic development of primordial germ cell-derived mouse embryonic germ cells in culture. Biochem Biophys Res Com 1999; 260: 475-482.

31 Yang J, Liao W, Ma Y. Role of SALL4 in hematopoiesis. Curr Opin Hematol 2012; 19: 287-291.

32 Nayernia K, Lee JH, Drusenheimer N, Nolte J, Wulf G, Dressel R et al. Derivation of male germ cells from bone marrow stem cells. Lab Invest 2006; 86: 654-663.

33 Lue Y, Erkkila K, Liu PY, Ma K, Wang Ch, Hikim AS et al. Fate of bone marrow stem cells transplanted into the testis. Am J Pathol 2007; 170: 899-908.

34 Vacanti MP, Roy A, Cortiella J, Bonassar L, Vacanti CA. Identification and initial characterization of spore-like cells in adult mammals. J Cell Biochem 2001; 80: 455-460.

35 Beltrami AP, Cesselli D, Bergamin N, Marcon P, Rigo S, Puppato E et al. Multipotent cells can be generated in vitro from several adult human organs (heart, liver, and bone marrow). Blood 2007; 110: 3438-3446.

36 Wakao S, Kitada M, Kuroda Y, Shigemoto T, Matsuse D, Akashi $\mathrm{H}$ et al. Multilineage-differentiating stress-enduring (Muse) cells are a primary source of induced pluripotent stem cells in human fibroblasts. Proc Natl Acad Sci USA 2011; 108: $9875-9880$

37 Jiang $Y$, Vaessen B, Lenvik T, Blackstad M, Reyes M, Verfaillie CM. Multipotent progenitor cells can be isolated from postnatal murine bone marrow, muscle, and brain. Exp Hematol 2002; 30: 896-904.

38 Kögler G, Sensken S, Airey JA, Trapp T, Müschen M, Feldhahn N et al. A new human somatic stem cell from placental cord blood with intrinsic pluripotent differentiation potential. J Exp Med 2004; 200: 123-135.

39 D'Ippolito G, Diabira S, Howard GA, Menei P, Roos BA, Schiller PC. Marrow-isolated adult multilineage inducible (MIAMI) cells, a unique population of postnatal young and old human cells with extensive expansion and differentiation potential. J Cell Sci 2004; 117: 2971-2981.

40 Shin DM, Liu R, Klich I, Wu W, Ratajczak J, Kucia M et al. Molecular signature of adult bone marrow-purified very small embryonic-like stem cells supports their developmental epiblast/germ line origin. Leukemia 2010; 24: 1450-1461.

41 Kassmer SH, Jin H, Zhang PX, Bruscia EM, Heydari K, Lee JH et al. Very small embryonic-like stem cells from the murine bone marrow differentiate into epithelial cells of the lung. Stem Cells 2013; 31: 2759-2766.

42 Havens AM, Sun H, Shiozawa Y, Jung Y, Wang J, Mishra A et al. Human and murine very small embryonic-like cells represent multipotent tissue progenitors, in vitro and in vivo. Stem Cells Dev 2014; 23: 689-701.

43 Virant-Klun I, Zech N, Rozman P, Vogler A, Cvjeticanin B, Klemenc P et al. Putative stem cells with an embryonic character isolated from the ovarian surface epithelium of women with no naturally present follicles and oocytes. Differentiation 2008; 76: 843-856.

44 Bhartiya D, Kasiviswananthan S, Shaikh A. Cellular origin of testis-derived pluripotent stem cells: a case for very small embryonic-like stem cells. Stem Cells Dev 2012; 21: 670-674. 
45 Ratajczak J, Zuba-Surma E, Klich I, Liu R, Wysoczynski M, Greco N et al. Hematopoietic differentiation of umbilical cord blood-derived very small embryonic/ epiblast-like stem cells. Leukemia 2011; 25: 1278-1285.

46 Shin DM, Zuba-Surma EK, Wu W, Ratajczak J, Wysoczynski M, Ratajczak MZ et al. Novel epigenetic mechanisms that control pluripotency and quiescence of adult bone marrow-derived Oct4(+) very small embryonic-like stem cells. Leukemia 2009; 23: 2042-2051.

47 Ratajczak MZ, Shin DM, Schneider G, Ratajczak J, Kucia M. Parental imprinting regulates insulin-like growth factor signaling: a Rosetta Stone for understanding the biology of pluripotent stem cells, aging and cancerogenesis. Leukemia 2013, 27: 773-779.

48 Kucia M, Masternak M, Liu R, Shin DM, Ratajczak J, Mierzejewska K et al. The negative effect of prolonged somatotrophic/insulin signaling on an adult bone marrow-residing population of pluripotent very small embryonic-like stem cells (VSELs). Age (Dordr) 2013; 35: 315-330.

49 Słuczanowska-Głąbowska S, Laszczyńska M, Piotrowska K, Głąbowski W, Rumianowski $B$, Masternak $M$ et al. The effect of calorie restriction on the presence of apoptotic ovarian cells in normal wild type mice and low-plasma-IGF-1 Laron dwarf mice. J Ovarian Res 2013; 6: 67.

50 Grymula K, Piotrowska K, Słuczanowska-Głąbowska S, Mierzejewska K, Tarnowski $M$, Tkacz $M$, et al. Positive effects of prolonged caloric restriction on the population of very small embryonic-like stem cells-hematopoietic and ovarian implications. J Ovarian Res 2014; 7: 68.

51 Bonig $\mathrm{H}$, Papayannopoulou T. Hematopoietic stem cell mobilization: updated conceptual renditions. Leukemia 2013; 27: 24-31.

52 Massberg S, Schaerli P, Knezevic-Maramica I, Köllnberger M, Tubo N, Moseman EA et al. Immunosurveillance by hematopoietic progenitor cells trafficking through blood, lymph, and peripheral tissues. Cell 2007; 131: 994-1008.

53 Wojakowski W, Landmesser U, Bachowski R, Jadczyk T, Tendera M. Mobilization of stem and progenitor cells in cardiovascular diseases. Leukemia 2012; 26: 23-33.

54 Borlongan CV. Bone marrow stem cell mobilization in stroke: a 'bonehead' may be good after all!. Leukemia 2011; 25: 1674-1686.

55 Dar A, Schajnovitz A, Lapid K, Kalinkovich A, Itkin T, Ludin A et al. Rapid mobilization of hematopoietic progenitors by AMD3100 and catecholamines is mediated by CXCR4-dependent SDF-1 release from bone marrow stromal cells. Leukemia 2011; 25: 1286-1296.

56 Katayama Y, Battista M, Kao WM, Hidalgo A, Peired AJ, Thomas SA et al. Signals from the sympathetic nervous system regulate hematopoietic stem cell egress from bone marrow. Cell 2006; 124: 407-421.

57 Lucas D, Bruns I, Battista M, Mendez-Ferrer S, Magnon C, Kunisaki $Y$ et al. Norepinephrine reuptake inhibition promotes mobilization in mice: potentia impact to rescue low stem cell yields. Blood 2012; 119: 3962-3965.

58 Ratajczak MZ, Kim CH, Wojakowski W, Janowska-Wieczorek A, Kucia M, Ratajczak J. Innate immunity as orchestrator of stem cell mobilization. Leukemia 2010; 24: 1667-1675.

59 Greenbaum AM, Link DC. Mechanisms of G-CSF-mediated hematopoietic stem and progenitor mobilization. Leukemia 2011; 25: 211-217.

60 Rettig MP, Ansstas G, DiPersio JF. Mobilization of hematopoietic stem and progenitor cells using inhibitors of CXCR4 and VLA-4. Leukemia 2012; 26: 34-53.

61 Borkowska S, Suszynska M, Mierzejewska K, Ismail A, Budkowska M, Salata D et al. Novel evidence that crosstalk between the complement, coagulation and fibrinolysis proteolytic cascades is involved in mobilization of hematopoietic stem/progenitor cells (HSPCs). Leukemia 2014; 28: 2148-2154.

62 Amara U, Flierl MA, Rittirsch D, Klos A, Chen H, Acker B et al. Molecular intercommunication between the complement and coagulation systems. J Immunol 2010; 185: 5628-5636.

63 Reis ES, Lange T, Köhl G, Herrmann A, Tschulakow AV, Naujoks J et al. Sleep and circadian rhythm regulate circulating complement factors and immunoregulatory properties of C5a. Brain Behav Immun 2011; 25: 1416-1426.

64 Lévesque JP, Helwani FM, Winkler IG. The endosteal 'osteoblastic' niche and its role in hematopoietic stem cell homing and mobilization. Leukemia 2010; 24 1979-1992.

65 Wysoczynski M, Kucia M, Ratajczak J, Ratajczak MZ. Cleavage fragments of the third complement component (C3) enhance stromal derived factor-1 (SDF-1) mediated platelet production during reactive postbleeding thrombocytosis Leukemia 2007; 21: 973-982.

66 Wysoczynski M, Reca R, Ratajczak J, Kucia M, Shirvaikar N, Honczarenko M et al. Incorporation of CXCR4 into membrane lipid rafts primes homing-related responses of hematopoietic stem/progenitor cells to an SDF-1 gradient. Blood 2005; 105: 40-48.

67 Guan JL. Cell biology. Integrins, rafts, Rac, and Rho. Science 2004; 303: 773-774.

68 Lapidot T, Kollet O. The brain-bone-blood triad: traffic lights for stem-cell homing and mobilization. Hematol Am Soc Hematol Educ Program 2010; 2010: 1-6.
69 Borkowska S, Poniewierska-Baran A, Schneider G, Suszynska M, Ratajczak J, Kucia, et al. Novel evidence that, in addition to proteolytic enzymes, lipolytic enzymes are involved in mobilization of hematopoietic stem/progenitor cells (HSPCs) -an important pro-mobilizing role identified for hematopoietic-specific phospholipase C (PLCß2). Blood 2014; 21: 2448

70 Ratajczak MZ, Lee H, Wysoczynski M, Wan W, Marlicz W, Laughlin MJ et al. Novel insight into stem cell mobilization-plasma sphingosine-1-phosphate is a major chemoattractant that directs the egress of hematopoietic stem progenitor cells from the bone marrow and its level in peripheral blood increases during mobilization due to activation of complement cascade/membrane attack complex. Leukemia 2010; 24: 976-985.

71 Golan K, Vagima Y, Ludin A, Itkin T, Cohen-Gur S, Kalinkovich A et al. S1P promotes murine progenitor cell egress and mobilization via S1P1-mediated ROS signaling and SDF-1 release. Blood 2012; 119: 2478-2488.

72 Juarez JG, Harun N, Thien M, Welschinger R, Baraz R, Pena AD et al. Sphingosine-1phosphate facilitates trafficking of hematopoietic stem cells and their mobilization by CXCR4 antagonists in mice. Blood 2012; 119: 707-716.

73 Kozuka T, Ishimaru F, Fujii K, Masuda K, Kaneda K, Imai T et al. Plasma stromal cell-derived factor-1 during granulocyte colony-stimulating factor-induced peripheral blood stem cell mobilization. Bone Marrow Transplant 2003; 31: 651-654.

74 Cecyn KZ, Schimieguel DM, Kimura EY, Yamamoto M, Oliveira JS. Plasma levels of FL and SDF-1 and expression of FLT-3 and CXCR4 on CD34+ cells assessed pre and post hematopoietic stem cell mobilization in patients with hematologic malignancies and in healthy donors. Transfus Apher Sci 2009; 40: 159-167.

75 Lee HM, Wu W, Wysoczynski M, Liu R, Zuba-Surma EK, Kucia M et al. Impaired mobilization of hematopoietic stem/progenitor cells in C5-deficient mice supports the pivotal involvement of innate immunity in this process and reveals novel promobilization effects of granulocytes. Leukemia 2009; 23: 2052-2062.

76 Wysoczynski M, Ratajczak J, Pedziwiatr D, Rokosh G, Bolli R, Ratajczak MZ. Identification of heme oxygenase $1(\mathrm{HO}-1)$ as a novel negative regulator of mobilization of hematopoietic stem/progenitor cells. Stem Cell Rev 2014; e-pub ahead of print; doi:10.1007/s12015-014-9547-7).

77 Lapidot T, Dar A, Kollet O. How do stem cells find their way home? Blood 2005; 106: 1901-1910.

$78 \mathrm{Ma}$ Q, Jones D, Springer TA. The chemokine receptor CXCR4 is required for the retention of $B$ lineage and granulocytic precursors within the bone marrow microenvironment. Immunity 1999; 10: 463-471.

79 Christopherson KW II, Hangoc G, Mantel CR, Broxmeyer HE. Modulation of hematopoietic stem cell homing and engraftment by CD26. Science 2004; 305: $1000-1003$

80 Onai N, Zhang Yy, Yoneyama H, Kitamura T, Ishikawa S, Matsushima K Impairment of lymphopoiesis and myelopoiesis in mice reconstituted with bone marrow-hematopoietic progenitor cells expressing SDF-1-intrakine. Blood 2000; 96: 2074-2080.

81 Ratajczak MZ, Kim CH, Abdel-Latif A, Schneider G, Kucia M, Morris AJ et al. A novel perspective on stem cell homing and mobilization: review on bioactive lipids as potent chemoattractants and cationic peptides as underappreciated modulators of responsiveness to SDF-1 gradients. Leukemia 2012; 26: 63-72.

82 Rossi L, Manfredini R, Bertolini F, Ferrari D, Fogli M, Zini R et al. The extracellular nucleotide UTP is a potent inducer of hematopoietic stem cell migration. Blood 2007; 109: 533-542.

83 Wysoczynski M, Reca R, Lee H, Wu W, Ratajczak J, Ratajczak MZ. Defective engraftment of $\mathrm{C} 3 \mathrm{aR}-/$ - hematopoietic stem progenitor cells shows a novel role of the C3a-C3aR axis in bone marrow homing. Leukemia 2009; 23: $1455-1461$.

84 Wu W, Kim CH, Liu R, Kucia M, Marlicz W, Greco N et al. The bone marrowexpressed antimicrobial cationic peptide LL-37 enhances the responsiveness of hematopoietic stem progenitor cells to an SDF-1 gradient and accelerates their engraftment after transplantation. Leukemia 2012; 26: 736-745.

85 Hoggatt J, Pelus LM. Eicosanoid regulation of hematopoiesis and hematopoietic stem and progenitor trafficking. Leukemia 2010; 24: 1993-2002.

86 Avigdor A, Goichberg P, Shivtiel S, Dar A, Peled A, Samira S et al. CD44 and hyaluronic acid cooperate with SDF-1 in the trafficking of human CD34+ stem/ progenitor cells to bone marrow. Blood 2004; 103: 2981-2989.

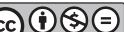

This work is licensed under a Creative Commons AttributionNonCommercial-NoDerivs 4.0 International License. The images or other third party material in this article are included in the article's Creative Commons license, unless indicated otherwise in the credit line; if the material is not included under the Creative Commons license, users will need to obtain permission from the license holder to reproduce the material. To view a copy of this license, visit http:// creativecommons.org/licenses/by-nc-nd/4.0/ 